\title{
Karyotype of a Japanese Salamander Hynobius katoi and Its Implication on Breeding Ecology (Amphibia: Caudata)
}

\author{
Kanto Nishikawa ${ }^{1 *}$, Masafumi Matsui ${ }^{1}$, Yasuhiro Kokuryo ${ }^{2}$ and Yasuchika Misawa ${ }^{3}$ \\ ${ }^{1}$ Graduate School of Human and Environmental Studies, Kyoto University, Yoshida-Nihonmatsu-cho, \\ Sakyo-ku, Kyoto 606-8501, Japan \\ ${ }^{2}$ Kori 1097-4, Fujieda, Shizuoka 426-0016, Japan \\ ${ }^{3}$ Civil Engineering and Eco-Technology Consultants, Higashi-ikebukuro 2-23-2, \\ Toshima-ku, Tokyo 170-0013, Japan
}

\begin{abstract}
Karyotype of a Japanese small salamander, Hynobius katoi, was first described. All individuals examined had $2 n=58$ chromosomes, consisting of nine pairs of biarmed macrochromosomes, four pairs of biarmed medium-sized chromosomes, six pairs of biarmed microchromosomes, and 10 pairs of uniarmed microchromosomes, although distinction of the second and the third groups of chromosome pairs was not clear. All pairs appeared homologous and no sexual dimorphism was found. Possession of $2 \mathrm{n}=58$ chromosomes in $\mathrm{H}$. katoi strongly suggests its lotic-breeding habits as was expected from the number and size of eggs and adult morphology. When compared morphology of chromosomes among loticbreeders with $2 n=58$ chromosomes, metacentric nature of No. 10 seems to characterize the karyotype of H. katoi.
\end{abstract}

Key words: Hynobius katoi, chromosome, karyotype, breeding habit, taxonomy

\section{INTRODUCTION}

Hynobius katoi is a small salamander recently described from central Japan whose breeding habits are unknown (Matsui et al., 2004).

Generally, species of the genus Hynobius are split into the lowland, still-water breeding type (lentic-breeder) and stream breeding type (lotic-breeder) (Sato, 1943). Matsui et al. (2004) inferred $H$. katoi to be a member of the loticbreeders, from its morphological and some reproductive characteristics (e.g. small clutch size, large, non-pigmented egg, and thick tail of metamorphs), and supposed unique breeding habit of underground breeding. However, the result of electrophoretic analysis indicated this species to be grouped unequivocally neither with lotic-breeding $H$. naevius and $H$. kimurae nor lentic-breeding $H$. tokyoensis compared (Matsui et al., 2004).

Karyotypes of all Japanese Hynobius salamanders except for $H$. katoi have already been examined, and the numbers of chromosomes are divided into the following three types, $2 \mathrm{n}=58[H$. boulengeri, $H$. kimurae, $H$. naevius, $H$. stejnegeri (lotic-breeders)], $2 \mathrm{n}=56[H$. abei, $H$. dunni, $H$. hidamontanus, $H$. lichenatus, $H$. nebulosus, $H$. nigrescens,

\footnotetext{
* Corresponding author. Phone: +81-75-753-6848;

Fax : +81-75-753-2891;

E-mail: hynobius@zoo.zool.kyoto-u.ac.jp
}

$H$. takedai, H. tokyoensis (lentic-breeders), and H. okiensis, $H$. tsuensis (lotic-breeders)], and $2 n=40$ [ $H$. retardatus (lentic-breeder)] [Seto and Matsui (1984), Seto et al. (1986), Ikebe et al. (1986), lizuka and Kakegawa (1989), Kuro-o et al. (2002) and references therein].

In contrast, karyotypes of congeners from outside of Japan are not studied well, but, from the data currently available, two groups are recognized: $2 n=56(H$. amjiensis, $H$. chinensis, $H$. leechi, $H$. quelpartensis and $H$. yangi from China and South Korea) and $2 n=58(H$. arisanensis, $H$. formosanus, and $H$. sonani from Taiwan)[Seto and Utsunomiya (1987), lizuka and Kakegawa (1989), Cha and Lee (1995), Ikebe et al. (1998), Kuro-o et al. (2002) and references therein]. Of these, species with $2 n=56$ chromosomes are all known to be lentic-breeders (Kim et al., 2003; Fei et al., 2005), while those with $2 n=58$ chromosomes are proved or strongly supposed to be lotic-breeders (Kakegawa et al., 1989).

Thus, the chromosome number roughly corresponds to the type of breeding, with most of lotic-breeders having $2 n=58$ chromosomes and all lentic-breeders having $2 n=56$ or 40 chromosomes.

From these lines of available information, karyological approach is expected to be an effective tool to estimate breeding habit of $H$. katoi. We thus examined the standard karyotype of this species. 


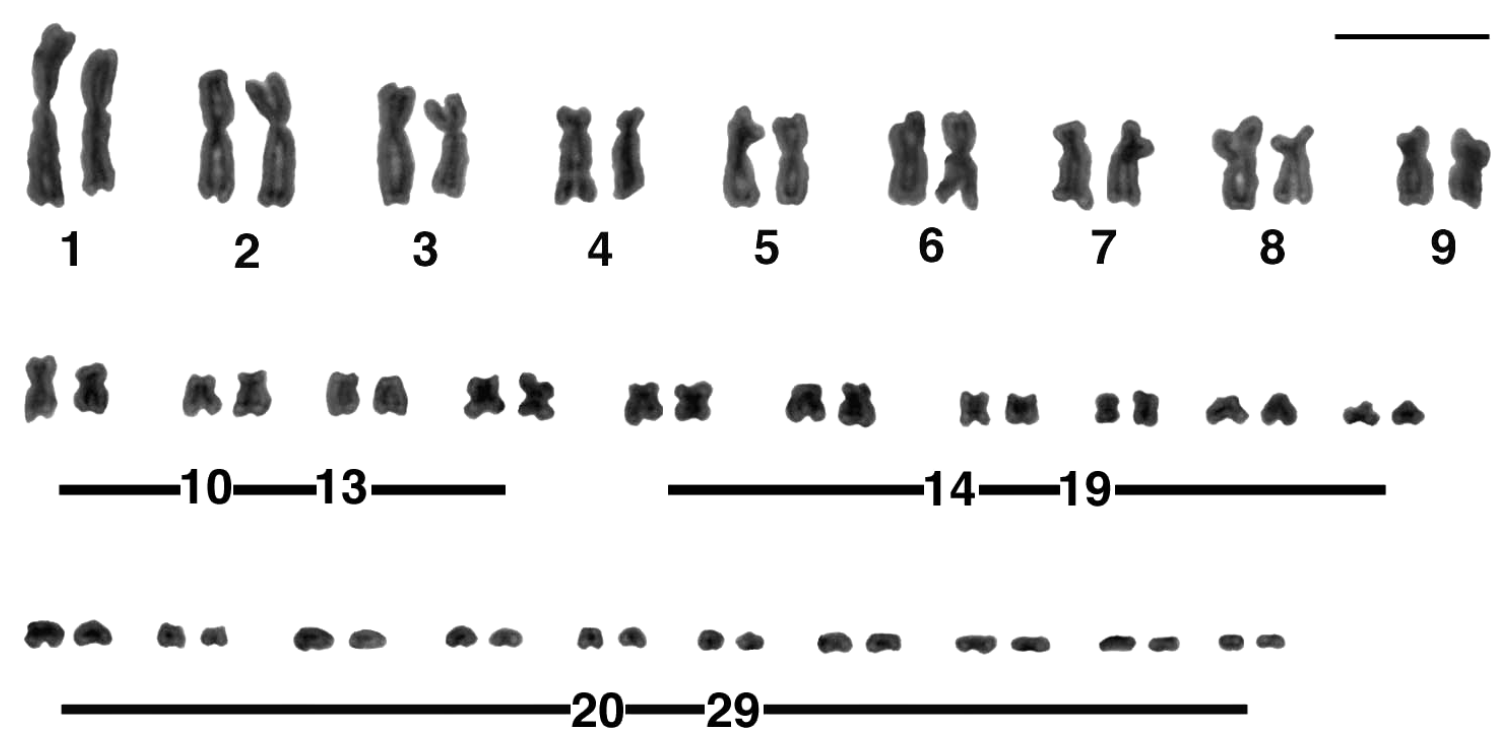

Fig. 1. The Giemsa stained karyotype of male Hynobius katoi from Misakubo-cho, Shizuoka Prefecture (KUHE 34789). A bar at the right top equals $10 \mu \mathrm{m}$.

\section{MATERIALS AND METHODS}

Chromosomal analyses were conducted on two males, one female, and two juveniles of $H$. katoi collected from Fujieda-shi (type locality) and Misakubo-cho of Shizuoka Prefecture from late April to early May. Sex was determined for each specimen by direct observation of gonads. Chromosomes were studied on the basis of squashed preparations of intestinal epithelium as described by Kezer and Sessions (1979) with a minor modification, using a 24 hour incubation period at $15^{\circ} \mathrm{C}$ after an intraperitoneal injection of colchicine solution $(0.2 \mathrm{mg} / \mathrm{ml})$. Colchicine-arrested metaphase chromosomes were stained with conventional $4 \%$ Giemsa solution. In the following description, the nomenclature follows Green et al. (1980). Voucher specimens are deposited in the Graduate School of Human and Environmental Studies, Kyoto University (KUHE 34753, 34789-90, 34792, 34883).

\section{RESULTS}

We obtained a total of 16 well-spread metaphase plates for all of the five individuals of $H$. katoi (Fig. 1). The diploid chromosome number was $2 n=58$. Sexual dimorphism was not observed at the Giemsa staining level. The 29 homologous pairs could be divided into four groups by size and shape (classification according to Seto et al., 1983 and Seto and Matsui, 1984) (Fig. 1). The first group contained large biarmed chromosomes (Nos. 1-9), of which Nos. 4 and 7 were subtelocentric, Nos. 8 and 9 were submetacentric, and the remaining five pairs were metacentric. Nos. 10-13 composed the second, medium-sized group of biarmed chromosomes in nearly equal sizes. This group contained one subtelocentric (No. 12), one submetacentric (No. 11), and two metacentric chromosomes (Nos. 10 and 13). Six pairs of the third group (Nos. 14-19) were biarmed (meta-, submeta- or subtelocentric) microchromosomes, of which two pairs (Nos. 14 and 15) were larger than the remaining pairs. The fourth group included 10 (Nos. 20-29) uniarmed (i.e., telocentric) microchromosomes.

\section{DISCUSSION}

The diploid number, $2 \mathrm{n}=58$, found in the present study of $H$. katoi indicates that this species shows karyological affinity with most of the lotic-breeding Hynobius species from Japan and Taiwan. This result agrees with the fact that $H$. katoi has other characteristics common to lotic-breeders (Matsui et al., 2004: see above) and strongly suggests that it is a member of lotic-breeders.

The karyotype of $H$. kato is unique in having metacentric No. 10 , because in other species with $2 n=58$ chromosomes, No. 10 is submetacentric $(H$. naevius, $H$. arisanensis, and $H$. sonani), subtelocentric $(H$. boulengeri and $H$. formosanus), or telocentric (H. kimurae) (lizuka and Kakegawa, 1989; Ikebe et al., 1986). No comparable information is available for $H$. stejnegeri (Seto and Matsui, 1984).

Of the six pairs of chromosomes composing the third size group in the H. katoi karyotype (i.e., Nos. 14-19), the two largest pairs, though referred to as microchromosomes here like the remainder, were actually intermediate in size between chromosomes composing the second size group and the other microchromosomes. Thus, although we followed conventional classification of $2 n=58$ chromosomes into four size groups (Seto et al., 1983), it is equivocal to separate the second and third groups in $H$. katoi based on the relative size of chromosomes contained.

Similar tendency is reported for Nos. 14 and 15 (lizuka and Kakegawa, 1989) or No. 14 alone (Ikebe et al., 1986) in H. kimurae, and No. 14 in H. naevius (lizuka and Kakegawa, 1989). By contrast, $H$. boulengeri (lkebe et al., 1986) and Taiwanese species with $2 \mathrm{n}=58$ chromosomes (lizuka 
and Kakegawa, 1989), have Nos. 14 and 15 that are similar in size with the remaining microchromosomes of the third group.

Electrophoretically, $H$. katoi was not always grouped with $H$. kimurae and $H$. naevius which have $2 n=58$ chromosomes (Matsui et al., 2004), probably these species have already achieved extremely great genetic differentiation from each other. Variations found among karyotypes of these species may support such an idea.

As mentioned above, the number of chromosomes, as well as some external characters in metamorphs, does not completely coincide with the breeding habit in the Hynobius salamanders. Indeed, $H$. okiensis from Dogo, Oki Islands and $H$. tsuensis from Tsushima Island are lotic-breeders, but they have $2 n=56$ chromosomes (Seto et al., 1986, 1987) like lentic-breeding congeners. In postmetamorphic morphology (e.g. flattened tail and thin limbs), the two species also resemble lentic-breeders with $2 n=56$ chromosomes rather than other lotic-breeding species.

Because phylogenetic relationships within Hynobius are not yet established, we cannot at present estimate the order of changes among breeding habit, morphology, and karyotype in each species of this genus. However, it is likely that lotic sites (i.e. small mountain streams) would have been more abundant than the lentic ones (e.g. paddies) in islands with steep geomorphology like Tsushima and Dogo (Oki), before the land was inhabited and exploited by human. If the breeding habits are less conservative than the adult morphology and/or chromosome number, these two insular species would have changed breeding sites from lentic to lotic ones. This hypothesis would be tested by future phylogenetic studies of the genus.

We could not detect sexually dimorphic pairs in our standard karyotype of $\mathrm{H}$. katoi, but a series of recent studies using various banding techniques (e.g. Kuro-o et al., 2002) revealed the microchromosome pair of No. 21 to be sexually dimorphic in some Hynobius species with $2 n=56$ chromosomes. Future applications of such techniques may reveal their presence in $\mathrm{H}$. katoi, as well as in other species with $2 n=58$ karyotypes.

\section{ACKNOWLEDGMENTS}

We thank Prof. T. Seto for his technical advice. We also thank two anonymous reviewers for improving an earlier version of the manuscript. This research was partly supported by grants from the Ministry of Education, Science and Culture, Japan (No. 11640697) and the Ministry of Environment to MM.

\section{REFERENCES}

Cha SH, Lee HY (1995) Polymorphism of NORs in Korean salamander, Hynobius leechii. Korean J Genet 17: 87-98

Fei L, Ye CY, Jiang JP, Xi F (2005) An Illustrated key to Chinese Amphibians. Sichuan Publ Group and Sichuan Publ House Sci Technol, Chengdu, China (in Chinese)

Green DM, Bogart JP, Anthony EH, Genner DL (1980) An interactive, microcomputer-based karyotype analysis system for phylogenetic cytotaxonomy. Comput Biol Med 10: 219-227

lizuka K, Kakegawa M (1989) Comparative karyology in five rare species of hynobiid salamanders from Taiwan and Japan. In "Current Herpetology in East Asia" Ed by M Matsui, T Hikida, RC Goris, Herpetol Soc Japan, Kyoto, pp 95-105

Ikebe C, Gu H, Ruan R, Kohno S (1998) Chromosome of Hynobius chinensis Günther and Hynobius amjiensis Gu from China, and comparison with those of 19 other Hynobius species. Zool Sci 15: 981-987

Ikebe C, Yamamoto T, Kohno S (1986) Karyotypes of two Japanese hynobiid salamanders, Hynobius kimurae Dunn and Hynobius boulengeri (Thompson). Zool Sci 3: 109-113

Kakegawa M, lizuka K, Kuzumi S (1989) Morphology of egg sacs and larvae just after hatching in Hynobius sonani and $\mathrm{H}$. formosanus from Taiwan, with an analysis of skeletal muscle protein compositions. In "Current Herpetology in East Asia" Ed by M Matsui, T Hikida, RC Goris, Herpetol Soc Japan, Kyoto, pp 147-155

Kezer J, Sessions SK (1979) Chromosome variation in the plethodontid salamander, Aneides ferreus. Chromosoma 71: 65-80

Kim JB, Min MS, Matsui M (2003) A new species of lentic breeding Korean salamander of the genus Hynobius (Amphibia, Urodela). Zool Sci 20: 1163-1169

Kuro-o M, lkebe C, Izumisawa Y, Fujinuki Y, Sasaki K, Saso K, Akaba K, Kohno S (2002) Cytogenetic studies of Hynobiidae (Urodela). XVIII. A ZZ/ZW sex-determining mechanism in a hynobiid salamander species, Hynobius tokyoensis Tago. Cytogenet Genome Res 99: 194-199

Matsui M, Kokuryo Y, Misawa Y, Nishikawa K (2004) A new species of salamander of the genus Hynobius from central Honshu, Japan (Amphibia, Urodela). Zool Sci 21: 661-669

Sato I (1943) A Monograph of the Tailed Batrachians of Japan. Nippon Shuppan-sha, Osaka (in Japanese)

Seto T, Matsui M (1984) Comparative karyology of five Japanese hynobiid species living in the mountain streams. Jpn J Genet 59: 654 (Japanese abstract)

Seto T, Matsui M, Kawakami E (1986) The Giemsa stained and Cbanded karyotypes of Hynobius tsuensis and $H$. leechii (Amphibia, Urodela). Jpn J Herpetol 11: 137-144

Seto T, Ouji M, Kuzumi S (1987) Karyotype analysis of Hynobius okiensis SATO, a salamander endemic to Dogo, Oki islands. San'in-chiiki-kenkyu 3: 1-6 (in Japanese with English abstract)

Seto T, Utsunomiya T (1987) Chromosome analysis of Hynobius arisanensis Maki, a salamander endemic to Taiwan. Herpetologica 43: 117-119

Seto T, Utsunomiya Y, Utsunomiya T (1983) Karyotypes of two representative species of hynobiid salamanders, Hynobius nebulosus (Schlegel) and Hynobius naevius (Schlegel). Proc Jpn Acad 59B: 231-235

(Received January 20, 2005 / Accepted May 26, 2005) 